\title{
Doulagem
}

\section{Uma atuação de resistência e democratização}

Talita Melgaço FERnANDES, Universidade Federal de Minas Gerais

Este artigo tem por objetivo mostrar como a prática da doulagem é um ato de resistência ao paradigma de assistência gravídico-puerperal hegemônico no Brasil, o tecnocrático. Para tanto é feita uma breve exploração sobre a história dos processos de gestar, parir e resguardar, destacando a apropriação destes pelas instituições médicas e como tal posicionamento proporcionou o florescimento da violência obstétrica. A figura das doulas é, neste trabalho, apresentada como um resgate a saberes ancestrais privativos aos círculos de mulheres e também mobilizada como uma estratégia de enfrentamento. Dois projetos de democratização do acesso à saúde, protagonizados por essas profissionais são descritos e discutidos de forma sintética, a saber, o Projeto Doulas Comunitárias realizado em Belo Horizonte - Minas Gerais, e o Projeto Doula a Quem Quiser planejado para operar na cidade do Rio de Janeiro - no estado de mesmo nome.

PALAVRAS-CHAVE: Assistência gravídico-puerperal. Violência Obstétrica. Doulas. Resgate. Resistências. 


\section{Introdução}

Esse artigo é parte de uma pesquisa de mestrado em andamento e busca organizar a experiência da doulagem como uma estratégia de resistência mobilizada pela rede de ativistas em prol do Movimento pela Humanização do Parto e do Nascimento (MHPN), frente a crescente violência obstétrica no Brasil. Destarte, faz-se necessário olhar para como o universo gravídico-puerperal, que compreende desde a concepção até o puerpério, passando pela gestação, perda, abortamento e parto, se consolidou ao longo da história recente da humanidade.

A medicina ocidental firmou-se galgando na esteira do pensamento iluminista e dentro de um sistema de saber e produção do conhecimento patriarcal, branco e elitista (MAIA, 2010). Assim sendo, também foi importado do referido campo, para o microcosmo das instituições de saúde, dos consultórios médicos, e das teorias sanitárias, vicissitudes provenientes dessas três lógicas de dominação. Por consequência, às pessoas negras, pobres e mulheres restaram espaços bem delimitados de atuação no campo médico e da saúde, de modo geral.

Em princípio, a mulher e sua fisiologia despertavam pouco fascínio nos estudos e práticas médicas. A saúde dessa parcela significativa da população foi, por muito tempo, assunto de interesse das próprias mulheres e seus círculos comunitários de cuidado, nos quais a cura e o saber eram de responsabilidade das mais experientes, em uma espécie de rede familiar e social (VIEIRA, 1999). Menstruar, gestar, abortar, nascer e morrer eram matérias rotineiras e privativas dessa rede, na qual destacavam-se as figuras das parteiras e das mulheresmães mais velhas.

O avanço da medicina, contudo, na expansão dos seus territórios, coloniza finalmente os corpos femininos que são inseridos no campo como objetos de experiência e submissão. Quando, ainda que sob contestação, as mulheres brasileiras passam, no século XIX, a adentrar o hospital para parir são deixados do lado de fora os seus pertences, seus familiares e também aquelas figuras que eram símbolo de cuidado, segurança e conforto (VIEIRA, 1999). E assim, de forma concomitante, mas também impulsionado pela revolução das tecnologias sanitárias, como os antibióticos e anestésicos, os processos fisiológicos femininos são ressignificados para o linguajar da patologia, para o ambiente hospitalar e para a lógica masculina (DINIZ; DUARTE, 2004). 
A esse tipo de dominação da autoridade médica Michel Foucault (2014) fora um dos pioneiros a endereçar como parte do regime de biopoder. Em "História da Sexualidade: a vontade do saber", o autor define poder como uma situação estratégica complexa que opera segundo correlações de força instáveis. O poder emana de todos os lugares e produz relações de dominação e de resistência. O biopoder é, por sua vez, essa conjuntura estratégica devotada ao direito de fazer viver e deixar morrer que opera segundo dois pólos, tendo entre eles uma infinidade de relações: o primeiro entende o corpo como máquina e está localizado no domínio das disciplinas anátamo-políticas do corpo humano e o segundo se concentra na mecânica do ser vivo como suporte aos processos biológicos, situando-se no ramo da biopolítica.

Para Foucault (2014), o papel social atribuído à mulher, como única, ou ao menos a princial, responsável pela saúde da prole, pela perpetuação da instituição familiar e pela salvação da sociedade transforma um corpo sujeito em um corpo objeto de interesse da medicalização, nos regimes de biopoder, subemetido a um processo designado como histerização. Na prática médica, observada pelo autor na Europa do século XIX, a moralidade se confunde com o discurso científico no intuito de, lastreada pela ciência, produzir "verdades" que serviam a política contemporânea do sexo, da reprodução e da sexualidade e silenciar várias outras. No campo do universo gravídicopuerperal também há uma série de autoras e autores que problematizam como o biopoder modificou a assistência prestada às mulheres (cf. BARBOSA, 2003; DINIZ, 2005; MAIA, 2010; VIEIRA, 1999). Aqui, todavia, me interessa analisar a resultante desse processo, em especial a configuração da violência obstétrica e, ainda seguindo a lógica foucaultiana, as resistências que se criaram a ela, através do reavivamento da atuação das doulas. Para tanto, farei uso da literatura existente acerca do tema, bem como de evidências científicas e duas experiências brasileiras, uma em Belo Horizonte (MG) e outra no Rio de Janeiro (RJ).

\section{Violência Obstétrica}

O atendimento obstétrico brasileiro hegemônico seria enquadrado com alguma facilidade no paradigma tecnocrático elaborado por Robbie Davis-Floyd (2001). Para a autora, é possível identificar na assistência ao parto três modelos de atenção, quais sejam, o tecnocrático, 
o humanista e o holístico. O tecnocrático se assenta de forma fundamental na concepção do corpo humano como máquina, imperfeita e passiva, que necessita da intervenção do profissional da medicina, e de todas as tecnologias disponíveis, para um desfecho positivo. Não há nesse modelo nada que se assemelhe a autonomia da usuária do sistema de saúde sobre o que se é feito ou decidido acerca da sua constituição, não há diálogo, ou relação de confiança, a mulher deve ser tutelada. É nessa compreensão intervencionista que atua grande parte dos profissionais relacionados à assistência ao ciclo gravídico-puerperal. Contudo, segundo Diniz e Duarte (2004), o que apontam revisões de estudos sistemáticas ainda deste século é que o uso exagerado de intervenções, tecnologia e partos cirúrgicos têm causado dor iatrogênica - aquela produzida pela própria assistência - e impacto negativo na saúde de mães e de bebês.

O paradigma tecnocrático que envolve a assistência à saúde da mulher no Brasil é a de um modelo violento e hostil. As pessoas que gestam passam de uma condição de pacientes para a de vítimas. Nesse sentido, a pesquisa "Mulheres brasileiras e gênero nos espaços público e privado" realizada por Venturi e colaboradores e publicada em 2010, afirma que cerca de 1 em 4 mulheres tinham sido violentadas durante o parto. No mesmo estudo, quando em situação de abortamento, a taxa de violência contra mulheres durante o atendimento subia para cerca de $53 \%$. A ocorrência de violações no sistema de atenção à saúde não é um fenômeno inócuo, pelo contrário, o atendimento desqualificado e o abortamento inseguro estão entres as cinco maiores causas de mortalidade materna no Brasil. Muitas dessas mortes atingem a população de forma desigual segundo vários vetores, em especial o de raça e o de classe (DINIZ, 2015; SEPPIR, 2017).

É diante desse panorama que se inicia uma consolidação em torno da expressão violência obstétrica. A conceituação desta varia conforme o contexto, uma vez que não há um imperativo legal no ordenamento brasileiro federal que a defina, restando o embate entre órgãos públicos das esferas municipais e estaduais, setores da sociedade civil e os Conselhos Regionais e Federais de medicina sobre a legitimidade e aplicabilidade do termo. Contudo, segundo revisão feita por Zanardo e Colaboradoras (2017), é comum que se faça uso dessa construção para se referir a violência contra mulheres gestantes dentro das instituições de saúde, podendo a violação ser física, psicológica, 
sexual ou por negligência. Adiante no mesmo texto as autoras destacam que,

[...] a violência obstétrica compreende o uso excessivo de medicamentos e intervenções no parto, assim como a realização de práticas consideradas desagradáveis e muitas vezes dolorosas, não baseadas em evidências científicas. Alguns exemplos são a raspagem dos pelos pubianos, episiotomias de rotina, realização de enema, indução do trabalho de parto e a proibição do direito ao acompanhante escolhido pela mulher durante o trabalho de parto. (ZANARDO et al., p. 5, 2017).

O Movimento pela Humanização do Parto e do Nascimento (MHPN), composto por diversos setores da sociedade, se coloca como grande questionador dessa maneira violenta de conceber, gestar, parir, nascer e resguardar no Brasil. O MHPN defende uma atenção em saúde ao ciclo gravídico-puerperal que se baseie no [1] protagonismo da mulher; [2] no cuidado multiprofissional e [3] na prática baseada em evidências científicas atualizadas (RATTNER, 2009). No seio desse movimento surgiram então algumas estratégias para lidar com a realidade obstétrica desalentadora. Na seção que segue, situo a doulagem como um desses artifícios.

\section{A Doulagem e seu Papel no Cenário Obstétrico Brasileiro}

O que na atualidade nos referimos como doulas são as mulheres, em geral mais experientes, que outrora auxiliavam as parteiras e as parturientes durante o trabalho de parto e parto (HORTA, 2008). Diferente das apanhadeiras/parteiras, as doulas não "realizam" partos, mas estão à disposição da parturiente para servi-la como ela necessitar, seja com um afago, com uma palavra de incentivo, oferecendo um alimento para revigorar as energias, ou mesmo ajudando na posição adotada para parir. Em grego, a palavra doula se refere aquela mulher que serve e assim elas fazem, não em um sentido de servidão como remete a palavra, mas naquele de amparo. Murilo Barbosa e colaboradoras (2018), definem essas profissionais como aquela "pessoa que dá suporte emocional à mulher intraparto, com treinamento específico sobre fisiologia do parto normal, métodos não farmacológicos para alívio da dor, cuidados pós-natais e aleitamento materno" (p. 421). Todavia, vê-se, com alguma frequência, a atuação das doulas iniciando- 
se ainda durante o pré-natal fornecendo, em especial, informações às gestantes e suas famílias sobre como transcorrem os processos de parto e pós-parto.

O papel da doula não se confunde com nenhum outro profissional do cenário do parto, como profissionais da obstetrícia, sejam médicos ou enfermeiros, anestesistas, neonatologistas, técnicos em enfermagem, dentre outros. Tampouco se confunde com o papel do acompanhante a que toda parturiente brasileira tem direito, conforme estabelece a lei federal $\mathrm{n}^{\mathrm{o}} \mathbf{1 1 . 1 0 8}$ de 2005 (PRESIDÊNCIA DA REPÚBLICA, 2005). A doula não tem responsabilidade técnica sobre os desfechos do trabalho de parto e parto e nem responde pela gestante ou por sua família. Ela está ali, munida do conhecimento sobre um processo natural do corpo humano, para amparar a pessoa que gesta, pare e se recupera do parto (mesmo que esse parto tenha sido uma perda ou abortamento).

Como já fora introduzido, com a passagem do parto de ritual doméstico para evento hospitalar figuras como as parteiras e as doulas ficaram restritas a atendimentos em comunidades mais remotas, pois sua entrada passou a ser negada nas instituições de saúde tradicionais (VIEIRA, 1999). Somente na última década do século XX que a doula passou a ser reincorporada no cenário de parto e o Hospital Sofia Feldman, em Minas Gerais, teve papel fundamental nesse fenômeno, como será explorado adiante. O próprio escopo de atendimento das doulas teve que se modificar conforme as novas tendências obstétricas. Resultado disso são doulas escoladas segundo as evidências científicas e com várias formações adicionais, como aleitamento materno, aromaterapia, cromoterapia, acupuntura, e toda sorte de terapias integrativas.

Sem dúvida, a doula é uma figura essencialmente diferente das demais no universo obstétrico hegemônico, por não compreender o processo sob a ótica da patologia e da intervenção constante, e como bem aponta Barbosa et al. (2018) esse é, muitas vezes, um ponto de tensionamento nas salas de parto. Em seu artigo o autor e as demais autoras retratam o quanto a estrutura de atenção hospitalar, mesmo a familiarizada com os pilares da humanização, é reticente à incorporação do trabalho dessas profissionais, em especial aquelas que adotam dentro das instituições de saúde um modus operandi de enfrentamento com as equipes e práticas assistenciais hegemônicas. Destarte, seria incorreto romantizar o trabalho desempenhado por estas como algo naturalmente 
belo e submisso, as doulas são atuantes e constantemente retaliadas pela sua atuação por aqueles que não compartilham, integralmente, da lógica do MHPN.

A mais recente revisão de estudos sistemática admitida na Biblioteca de Cochrane, até então, realizada por Bohren et al. (2017), indica que o suporte contínuo, como o exercido por doulas, durante o trabalho de parto e parto aumenta a probabilidade de desfechos positivos para mãe e para bebês e aponta a inexistência de consequência negativa nos estudos analisados. Os benefícios compreendem o aumento da chance de partos vaginais espontâneos, da satisfação quanto a via de parto, e das pontuações de Apgar ${ }^{1}$, bem como a diminuição do uso de analgésicos, anestésicos, partos instrumentais e duração do trabalho de parto. Há, também, indícios, ainda que mais fracos, da diminuição da depressão pós-parto. O que as evidências suportam é que apesar dos tensionamentos que as doulas provocam na assistência ao parto a sua atuação tem impacto positivo na saúde das usuárias envolvidas. Se a presença dessas profissionais intraparto não é suficiente para coibir a violência obstétrica ao menos parece indicar que converge com o aumento das boas práticas no atendimento.

Cabe ressaltar que os estudos analisados na revisão supracitada não se propunham a observar a relação entre fazer acompanhamento pré-natal com uma doula e os processos e desfechos dos partos, tendo assim uma impossibilidade de avaliar o impacto da orientação informacional e preparatória fornecido por essas profissionais, bem como não foram a fundo nos atendimentos ao longo do puerpério. Também é importante enfatizar que embora um estudo utilizado na revisão tenha sido feito no Brasil, país líder das cirurgias cesarianas, a presença de países com índices menores de intervenção pode ter alterado o resultado de uma possível revisão privativa a realidade deste país.

Para além do lugar da evidencia, há também o lugar da memória e afetividade na atuação de resistência das doulas no Brasil. Em "Doulas como dispositivos para humanização do parto hospitalar: do voluntariado à mercantilização”, Barbosa e colaboradoras (2018)

1 Esse é o nome dado à avaliação clínica do recém-nascido, feita nos seus primeiros 5 minutos de vida. O método foi proposto por Virginia Apgar em 1953 e 1958, consiste na observação de 5 fatores, são eles, cor da pele, tônus muscular, pulsação arterial, irritabilidade reflexa, esforço respiratório que são avaliados no primeiro e no quinto minuto de vida, tendo muita utilidade para analisar a necessidade da ressuscitação do bebê nesse período (APGAR, 1953). 
apresentam as motivações das mulheres ao se tornarem doulas. Todos elas estão envoltas de certa empatia para com a condição de mulheres gestantes, mas a motivação do chamado difere desde uma vocação religiosa até uma linhagem familiar de mulheres que cuidam umas das outras. Um incentivo específico, observado no estudo de Barbosa et al. (2018) e que encontra correspondência na pesquisa de mestrado da qual deriva o presente artigo, coloca essas mulheres no centro da luta pelo MHPN e merece destaque, a saber, a motivação daquelas que decidiram serem doulas para proporcionarem uma experiência positiva que não tiveram possibilidade de viver em seus próprios partos devido à incidência da Violência Obstétrica. Há aqui um aspecto dual de enfrentamento dessas figuras, ao mesmo tempo em que se tornam profissionais para serem agentes das boas práticas, também entram na profissão para sanar suas próprias feridas. A seguir apresento duas experiências de doulagem que intencionam impactar o atendimento às mulheres usuárias em prol da humanização, uma mais consolidada em Belo Horizonte e outra em fase de implementação do Rio de Janeiro.

\section{Projeto Doulas Comunitárias e o Projeto Doula a Quem Quiser}

O "projeto doulas comunitárias" que vigora no município de Belo Horizonte, no estado de Minas Gerais, é a extensão da experiência de inserção de doulas em um hospital específico da cidade, o Hospital Sofia Feldman (HSF). Quando o projeto teve início o HSF ainda era uma maternidade de médio porte com cerca de 60 leitos, hoje a instituição é uma das maiores maternidades públicas do país. A realidade que fomentou a criação do projeto era a de mulheres gestantes, muitas em situação de vulnerabilidade, que davam entrada na entidade em trabalho de parto, mas que seguiam desacompanhadas durante toda a assistência da equipe de saúde. Portanto, visando mitigar as distorções de um parto solitário e dar a todas as mulheres, independente de condição socioeconômica ou racial, o direito de um parto mais próximo ao que se convenciona em organismos internacionais, como a Organização Mundial da Saúde (OMS), é que se instaura o referido Projeto. (LEÃ̃O; BASTOS, 2001; HSF, 2019a; HSF, 2019b).

Nesse contexto, em 1997, foram selecionadas, com auxílio da Associação Comunitária de Amigos e Usuários do Hospital Sofia Feldman (ACAU/HSF) e a direção hospitalar, 14 doulas voluntárias, 
dentro da comunidade atendida pela Maternidade, que segundo Leão e Bastos (2001) tinham o perfil de mulheres saudáveis (física e mentalmente), maiores de 21 anos, residentes nas cercanias do HSF, calmas, caridosas, solidárias, discretas, de fácil convivência, dentre outros pré-requisitos. Essas mulheres foram treinadas acerca da fisiologia do parto e sobre as estruturas e condutas do hospital e uma vez formadas passaram a trabalhar em plantões de 12 horas, com ajuda de custo para transporte e alimentação.

Júlia Horta (2008) publicou, posteriormente, uma análise da vivência dessas mulheres-doulas atuantes no HSF evidenciando as satisfações e os desafios dos atendimentos e a relação, em sua maioria, positiva construída com a equipe daquela instituição. Embora não houvesse, no país, um estudo sistemático que apresentasse dados sobre o impacto dessas profissionais, em 2003, o Projeto foi ampliado nacionalmente via convênio com o Ministério da Saúde e passou, em 2007, a ser realidade nas demais maternidades públicas do município de Belo Horizonte através da Comissão Perinatal (cf. LANSKY, 2010; PBH, 2007; RATNNER, 2009). Algumas interpretações podem ser feitas diante da postura federal e municipal com relação a valorização da doula enquanto profissional, nesse contexto em específico. A primeira delas aponta para um compromisso interno de erradicar as desigualdades perpetuadas no âmbito da saúde e a segunda aponta para um alinhamento com os protocolos da OMS e demais dispositivos internacionais que já discutiam o possível benefícios da atuação das doulas. Além do mais, a expansão da doula na rede pública, evidencia uma ação taxativa de democratização do direito ao acesso à mais qualificada assistência de saúde, pois recoloca a doula no cenário como uma ferramenta de conforto à todas as usuárias, não somente àquelas que podem pagar pelo serviço.

Caminhando também para uma acesso equânime e justo à saúde é que se desenvolve o Projeto Doula a Quem Quiser, encabeçado pela Associação de Doulas do Rio de Janeiro (ADoulasRJ). O objetivo proposto é que mulheres privadas de liberdade também tenham o seu direito de ser assistida por doulas durante a sua gestação, parto e puerpério exercido, mas, e principalmente, que essa população tenha ciência sobre os seus direitos e possam assim identificar e denunciar situações de violência obstétrica que sabidamente afetam, de forma categórica, grupos em situação de vulnerabilidade, como a comunidade encarcerada (cf. DINIZ, 2015). A área de incidência é o complexo do 
Gericinó, com ênfase no Presídio Talavera Bruce e na Unidade Materno Infantil Madre Tereza de Calcutá, e o projeto prevê, como alguma de suas abordagens, a realização de rodas com as detentas e a distribuição de cartilhas (ADoulasRJ, 2018). Em 2019, a AdoulasRJ assinou um termo de cooperação com o a Defensoria Pública daquele estado a fim de ampliar o projeto para outras localidades (DPRJ, 2019).

Diferentemente, do que acontece na legislatura belo-horizontina - sob a qual se protocolou a lei 10.914 de 2016 que obriga as maternidades públicas e privadas a aceitarem a entrada das doulas durante todo o trabalho de parto e parto $(\mathrm{PBH}, 2016)$ e outra, a lei 23.175 de 2018, no âmbito estadual, de combate a violência obstétrica (ALMG, 2018) -, a relação entre o poder público e médico no município do Rio de Janeiro e a categoria das doulas e demais profissionais engajados no MHPN é turbulenta. Depois de muito embate na câmara municipal do Rio de Janeiro a lei que permite a entrada das doulas foi vetada pelo então prefeito Crivella em meados de 2017 (FÉLIX, 2017), contrariando, inclusive, a lei estadual de número 7.314, de teor parecido aprovada em 2016 (ALERJ, 2016). Felizmente para as oficiais da doulagem, em seguida, o veto conseguiu ser derrubado (TVT, 2017).

Mais recentemente, em 2019, o Conselho Regional de Medicina do Rio de Janeiro emitiu resolução que proíbe os médicos de aceitarem o plano de parto, documento em que as gestantes manifestam as suas preferência de opções de tratamento (BAIMA, 2019). O mesmo órgão foi responsável, em 2016, por duas outras resoluções: uma que proibia os médicos de realizarem atendimento de partos em domicílio e outra que proibia a entrada de pessoas não formadas na área de saúde nas salas de cirurgia no momento do parto, afetando especialmente as doulas e desafiando a legislação federal sobre a presença do acompanhante (GUSMÃO, 2016). Em Belo Horizonte, por sua vez, o ano de 2017 marcou uma cisão entre o MHPN local e a gestão municipal, com a dissolução da Comissão Perinatal e a constituição de uma Coordenação Perinatal, composta somente por gestores remunerados e distantes do Movimento.

O que os exemplos revelam são duas localidades diferentes que apresentam um relacionamento com as profissionais da doulagem de maneira muito distinta. Se no primeiro projeto a iniciativa surge do próprio hospital ainda que buscando nas voluntárias um perfil de docilidade passível de controvérsias, no segundo vê-se claramente o enfrentamento da categoria diante de forças conservadoras já 
consolidadas e o próprio poder público. Também é possível acompanhar um mudança de postura dos atores envolvidos ao longo do tempo em ambos os recortes, haja vista os retrocessos na capital mineira perante a gestão municipal e o avanço na capital carioca no diálogo com a defensoria pública. Se as condições mudam, podemos, haja vista a movimentação dessa profissionais, afirmar que o objetivo das doulas belo-horizontinas e cariocas preserva uma semelhança que é a de levar a mais mulheres a possibilidade de um parto positivo, digno e respeitoso.

\section{Considerações Finais}

Em a História da Sexualidade volume I, Michel Foucault (2014) diz que as resistências se desenvolvem de forma relacional ao poder hegemônico que é o que regula o sexo, a sexualidade, a reprodução e o prazer, portanto quem resiste frequentemente está desafiando essa lógica, ainda que opere dentro dos constrangimentos dela. Estudiosos das Teorias dos Movimentos Sociais fazem menção a formas mobilizadas por movimentos para superar as situações diagnosticadas por esses como insatisfatórias, frequentemente falam-se de denúncias, protestos, desobediência civil, para caracterizar as estratégias utilizadas (cf. GOHN, 2011; GOHN, 2012). O que aqui proponho é que a doulagem, seja cooperando até determinado nível com alguns aspectos institucionais como acontece no HSF ou enfrentando explicitamente o sistema hegemônico como por vezes se coloca a ADOULASRJ, é uma atuação de resistência. Aqui o ato de resistir toma contornos, por vezes, mais implícitos, lembrando a maneira como James Scott (1990) trata o termo, perpetuando uma prática ancestral em um paradigma em que ela não é bem quista. Considerando que para um regime democrático é incompatível uma estrutura de subjugação dos sujeitos (BIROLI, 2014), a doula pode ser lida como uma ferramenta de democratização dentro e fora das salas de parto, especialmente para populações em situação de vulnerabilidade como as atingidas pelos projetos supracitados.

\section{Referências}

ADoulasRJ - ASSOCIAÇÃO DE DOULAS DO RIO DE JANEIRO. Conheça o projeto Doula a Quem Quiser. 2018. Disponível em: $<$ https://doulasrj.com.br/2018/o9/14/conheca-o-projeto-doula-aquem-quiser/>. Acesso em 10 jan. 2019 
ALERJ - ASSEMBLEIA LEGISLATIVA DO RIO DE JANEIRO. LEI $N^{o}$ $7314 D E 15 D E$ JUNHO 2016. Rio de Janeiro, 2016. Disponível em: <http://alerjln1.alerj.rj.gov.br/contlei.nsf/ c 8 a a o 9 o o o $25 \mathrm{f}$ e e f 6032564 e c o o 6 o d f f f / f6a4bdfe5bb46c4383257fd4005a506c?OpenDocument>. Acesso em: 15 jan. 2019.

ALMG - ASSEMBLEIA LEGISLATIVA DE MINAS GERAIS. LEI 23175, $D E$ 21/12/2018. Belo Horizonte, 2018. Disponível em: <https:// www.almg.gov.br/consulte/legislacao/completa/completa.html? ano=2018\&num=23175\&tipo=LEI $>$. Acesso em: 28 dez. 2018.

APGAR V. A proposal for a new method of evaluation of the newborn infant. Curr Res Anesth Analg. 1953;32(4):260-267.

BAIMA, C. Resolução do Cremerj causa revolta em defensores do parto humanizado. O Globo. Rio de Janeiro, 2019. Disponível em: <https:// oglobo.globo.com/sociedade/resolucao-do-cremerj-causa-revolta-emdefensores-do-parto-humanizado-23440403 >. Acesso em o9 fev. 2019.

BALASKAS, J. Parto Ativo: guia prático para o parto natural (a história e filosofia de uma revolução). 3. ed. São Paulo: Ground, 2015.

BARBOSA, G. P. et al. Parto cesáreo: quem o deseja? Em quais circunstâncias? Cadernos de Saúde Pública, 19(6): 1.611-1.620, 2003.

BARBOSA, M. B. B. et al. Doulas como dispositivos para humanização do parto hospitalar: do voluntariado à mercantilização. Saúde em Debate, Rio de Janeiro, v. 42, n. 117, p. 420 - 429, Abr - Jun 2018. Disponível em: <http://www.scielo.br/pdf/sdeb/v42n117/o103-1104sdeb-42-117-0420.pdf $>$. Acesso em 07 de nov. 2018.

BIROLI, F. Autonomia, Dominação e Opressão. In: MIGUEL, L. F.; BIROLI, F. Feminismo e Política. 1. ed. São Paulo, Boitempo, 2014. cap. 7, p. 109-122.

BOHREN, M. A. et al. Continuous support for women during childbirth. Cochrane Database of Systematic Reviews 2017, Issue 7. Art. No.: CDo03766. DOI: 10.1002/14651858.CDo03766.pub6. 
DAVIS-FLOYD, R. The technocratic, humanistic, and holistic paradigms of childbirth. International Journal of Gynecology \&amp; Obstetrics, 75: S5-S23, 2001.

DINIZ, C. S. G. Humanização da assistência ao parto no Brasil: os muitos sentidos de um movimento. Ciência \&amp; saúde coletiva, Rio de Janeiro , v. 10, n. 3, p. 627-637, Set. 2005. Disponível em: <http:// www.scielo.br/scielo.php? script $=$ sci_arttext\&amp; pid $=S 1413-$ 81232005000300019\&amp;lng=en\&amp;nrm=iso>. Acessado em 06 ago. 2017.

DINIZ, S. G.; DUARTE, A. C. Parto normal ou cesárea? O que toda mulher deve saber (e todo homem também). Editora UNESP, 2004.

DINIZ, C. S. G. et al. Violência obstétrica como questão para a saúde pública no Brasil: origens, definições, tipologia, impactos sobre a saúde materna, e propostas para sua prevenção. Revista Brasileira de Crescimento e Desenvolvimento Humano. 2015;25(3):377-84.

DPRJ - DEFENSORIA PÚBLICA DO ESTADO DO RIO DE JANEIRO. DPRJ celebra parceria com Associação de Doulas do Rio de Janeiro. Rio de Janeiro, 2019. Disponível em: < http://www.defensoria.rj.def.br/ noticia/detalhes/9398-DPRJ-celebra-parceria-com-Associacao-deDoulas-do-Rio-de-Janeiro >. Acessado em set. 2019.

FELIX, P. Crivella veta projeto que permite doulas em hospitais cariocas. O Estado de São Paulo, São Paulo, 2017. Disponível em: <https://saude.estadao.com.br/noticias/geral,crivella-veta-projeto-quepermite-doulas-em-hospitais-cariocas,70002099437>. Acesso em 17 jan. 2019.

FOUCAULT, M. História da sexualidade 1: A vontade de saber. 7. ed. Rio de Janeiro/São Paulo: Paz e Terra, 2014.

GOHN, M. G. M. Movimentos sociais na contemporaneidade. Revista Brasileira de Educação, vol.16, no.47, p.333-361, Ago 2011.

Novas teorias dos movimentos sociais. 4. ed. São Paulo: Edições Loyola, 2012. 
GUSMÃO, M. de C. As doulas e o parto humanizado. Jus, 2016. Disponível em: < https://jus.com.br/artigos/48555/as-doulas-e-oparto-humanizado >. Acesso em 17 jan. 2019.

HORTA, J. A. A doula comunitária: uma experiência reinventada. Dissertação (Mestrado em Ciências da Saúde) - Faculdade de Medicina, Universidade Federal de Minas Gerais. Belo Horizonte, 161f, 2008.

HSF - HOSPITAL SOFIA FELDMAN. Maternidade. Disponível em: <http://www.sofiafeldman.org.br/atencao-a- mulher/maternidade/>. Acesso em: 15 de dez. 2018a.

. Doula. Disponível em: <http://www.sofiafeldman.org.br/ atencao-a-mulher/doula/>. Acesso em: 15 de dez. 2018b.

LANSKY, S. Gestão da qualidade e da integralidade do cuidado em saúde para a mulher e a criança no SUS-BH: a experiência da comissão perinatal. Revista Tempus Actas de Saúde Coletiva, 2010.

LEÃO, M. R. C.; BASTOS, M. A. R. Doulas apoiando mulheres durante o trabalho de parto: experiência do Hospital Sofia Feldman. Rev Latinoam Enfermagem. 2001; 9(3).

MAIA, M. B. Humanização do Parto: política pública, comportamento organizacional e ethos profissional. Rio de Janeiro: Editora Fiocruz, 2010.

PREFEITURA MUNICIPAL DE BELO HORIZONTE, PBH. SOS Saúde Projeto "Doulas Comunitárias". 2007. Disponível em: <http:// portalpb h-hm.pb . gov.br/pbh/ecp/contents.do? evento $=$ conteudo\&idConteudo $=25677 \& \mathrm{chPl} c=25677 \&$ viewbusca $=\mathrm{s}>$. Acesso em: 10 jan. 2019.

. LEI No 10.914, DE $1 O$ DE MARÇO DE 2016. Disponível em: < http:/ / portal6.pb h.gov.br/dom / in icia Edicao.do? method=DetalheArtigo\&pk=1159375>. Acessado em out 2018.

PRESIDÊNCIA DA REPÚBLICA. LEI $N^{o} 11.108, D E 7 D E$ ABRIL DE 2005. 2005. Disponível em: < http://www.planalto.gov.br/ccivil_03/ _ato2004-2006/2005/lei/l11108.htm>. Acessado em out 2017. 
RATTNER, D. Humanização na atenção a nascimentos e partos: ponderações sobre políticas públicas. Revista Interface, Botucatu, v. 13, p. 759-768, 2009. Disponível em: < http://www.scielo.br/scielo.php? script $=$ sci_arttext\&pid $=\mathrm{S} 1414-32832009000500027>$. Acessado em out 2017.

SCOTT, J. C. Domination and the arts of resistance: hidden transcripts. Ann Arbor: Yale University Press, 1990.

SEPPIR - SECRETARIA ESPECIAL DE POLÍTICAS DE PROMOÇÃO DA IGUALDADE RACIAL. Racismo é apontado como uma das causas da mortalidade materna entre mulheres negras. Disponível em: <http:// www.seppir.gov.br/central-de- conteudos/noticias/junho/racismo-eapontado-como-uma-das-causas-da-mortalidade-materna- entremulheres-negras $>$. Acessado em 10 ago. 2017.

TVT. Vitória das Doulas no RJ: PL derruba decisão de Crivella e permite acompanhamento no parto. Disponível em: <http:// www.tvt.org.br/vitoria-das-doulas-no-rj-pl-derruba-decisao-de-crivellae-permite-acompanhamento-no-parto/>. Acesso em 17 jan. 2019.

VENTURI, G.; RECAMÁN, M; OLIVEIRA, S. (orgs). Pesquisa mulheres brasileiras nos espaços público e privado. São Paulo: Fundação Perseu Abramo, 2010.

VIEIRA, E. M., 1999. A medicalização do corpo feminino. In: Questões de Saúde Reprodutiva (K. Giffin \&amp; S. H. Costa, org.), pp. 67-78, Rio de Janeiro: Editora Fiocruz.

ZANARDO, G. L. P et al. Violência obstétrica no Brasil: uma revisão narrativa. Psicologia \& Sociedade. v. 29, Belo Horizonte: 2017. 


\section{The role of doula: an act of resitance and democratization}

ABSTRACT: This article aims to show how the practice of doulas is an act of resistance to the hegemonic paradigm of pregnancy and puerperal care in Brazil. In order to do so, a brief exploration is made of the history of gestation, birth and postpartum process, and the appropriation of it by medical institutions and the effect of the birth of the category of obstetric violence. The figure of the doulas is presented in this work as a rescue of ancestral knowledge exclusive to women's circles and also mobilized as a coping strategy. Two projects to democratize access to health role played by these professionals are described and discussed in a synthetic way, namely the Doulas Comunitárias Project, held in Belo Horizonte - Minas Gerais, and the Doula a Quem Quiser Project, which is planned to operate in the city of Rio de Janeiro - in the state of the same name.

KEYWORDS: Pregnancy and puerperal care. Obstetric Violence. Doulas. Rescue. Resistance.

Talita Melgaço FERNANDES

Feminista, negra, doula, bacharela em Relações Internacionais pela Universidade de Brasília e mestranda em Ciência Política pela Universidade Federal de Minas Gerais. Contato via: mfernandes.talita@gmail.com.

Recebido em: 10/02/2019

Aprovado em: 26/12/2019 